\title{
Comparative ototoxicity of gentamicin in the guinea pig and two strains of rats
}

\author{
Michael J. Sullivan ${ }^{1,2}$, Kyle E. Rarey ${ }^{1, *}$ and Rory B. Conolly ${ }^{2, * *}$ \\ 'Kresge Hearing Research Institute, University of Michigan Medical School, Ann Arbor, U.S.A. \\ and ${ }^{2}$ Toxicology Program, School of Public Health, The University of Michigan, Ann Arbor. U.S.A.
}

(Received 6 October 1986; accepted 30 August 1987)

\begin{abstract}
Gentamicin ototoxicity and nephrotoxicity were compared in two strains of rats. Sprague-Dawley and Fisher-344, and in the Hartley albino guinea pig. Treatment groups consisting of 8 male rats of each strain and four male guinea pigs were dosed subcutaneously for 14 days with either 80 or $100 \mathrm{mg} / \mathrm{kg}$ of gentamicin sulfate in saline. Brainstem auditory evoked response (BAER) thresholds were recorded from each animal in each group on day 11 post-administration. Blood urea-nitrogen and scrum creatinine were measured in blood obtained on day 11 post-administration as measures of nephrotoxicity. Kidney weight/body weight ratios were also determined. Loss of sensory hair cells was observed in the basal region of the organ of Corti from all animals treated with $100 \mathrm{mg} / \mathrm{kg}$ of gentamicin. The hair cell loss and BAER threshold elevations were greatest in the guinea pigs. Fisher-344 rats showed more extensive hair cell loss and greater BAER threshold elevations than Sprague-Dawley rats. The Fisher-344 rats exhibited increased blood urea-nitrogen and kidney weight/body weight ratios. Sprague-Dawleys did not suffer any nephrotoxic effects. These data indicate that the Fisher-344 rat is a useful animal in which to study aminoglycoside ototoxicity as it exhibits both functional and morphological changes after gentamicin administration.
\end{abstract}

Gentamicin; Ototoxicity; Rat; Guinea pig; Brainstem auditory evoked response

\section{Introduction}

The guinea pig and chinchilla have been used extensively in behavioral, physiological and morphological studies of the mechanisms of hearing loss (Hawkins, 1976). In ototoxicological investigations, the rat may offer certain advantages over the guinea pig and chinchilla. The rat is easier to breed and less expensive than either the guinea pig or the chinchilla. Furthermore, the rat is the animal most widely used in toxicological studies. However, there have been few published reports comparing the sensitivity of the rat to ototoxicants with that of the guinea pig or chinchilla. The

Correspondence (present address) to: M.J. Sullivan, NCASI, 260 Madison Ave., 1105, New York, NY 10016, U.S.A.

* Present address: Department of Anatomy, University of Florida, Gainesville, FL 32610, U.S.A.

** Present address: Northrup Services Inc., Environmental Sciences, 101 Woodman Dr., Suite 12, Dayton, OH 45431 , U.S.A. purpose of this investigation was to compare the relative sensitivity of two rat strains with that of Hartley albino guinea pigs to the ototoxic aminoglycoside gentamicin. Gentamicin sensitivity in these animals was compared with respect to ototoxicity, nephrotoxicity and body weight gain.

\section{Materials and Methods}

\section{Reagents}

Gentamicin sulfate, with a potency of 583 $\mu \mathrm{g} / \mathrm{mg}$, was purchased from Sigma Chemical $\mathrm{Co}$. (St. Louis, MO). All other reagents were of analytical grade.

\section{Animals}

Male Sprague-Dawley rats $(175-200 \mathrm{~g} . n=20)$. male Fisher-344 rats $(125-150 \mathrm{~g}, n=20)$ and male Hartley albino guinea pigs $(275-300 \mathrm{~g}, n=12$, Charles River Laboratories, Inc., Portage, MI) were housed two per cage in hanging metal cages 
and given water and either guinea pig or rodent chow (Ralston Purina Co.) ad libitum. The animal quarters were maintained at $22^{\circ} \mathrm{C}$ on a $12 \mathrm{~h}$ light/dark cycle. Animals were acclimatized for one week prior to use. The treatment groups consisting of 8 Sprague-Dawley, 8 Fisher- 344 rats and 4 guinea pigs were dosed subcutaneously once daily for 14 days with either 80 or $100 \mathrm{mg} / \mathrm{kg}$ of gentamicin sulfate in saline. Gentamicin solutions were formulated at 80 and $100 \mathrm{mg} / \mathrm{ml}$ so that each rat received $1.0 \mathrm{ml}$ dosing solution $/ \mathrm{kg}$ body wt. Sealed vials of the gentamicin dosing solution were prepared and stored at $4^{\circ} \mathrm{C}$ until use. The four control animals of each group received saline subcutaneously. Body weights were recorded each day. Animals were observed each day for signs of vestibular toxicity: loss of righting reflex and normal gait.

\section{Functional measure}

Brainstem auditory evoked response (BAER) thresholds were recorded from each animal of each treatment group and all controls in a sound attenuated box on the eleventh day post-administration. The 11 day period was used to provide time for any gentamicin-induced inner ear damage to be manifested. Animals were anaesthetized with an intraperitoneal injection of ketamine hydrochloride (Ketaset, $50 \mathrm{mg} / \mathrm{kg}$ ) and xylazine (Rompun, $10 \mathrm{mg} / \mathrm{kg}$ ). Additional doses $(1 / 4$ original dose) were given as needed to maintain a stable state of anaesthesia. The recording electrode configuration consisted of three small (26 gauge) hypodermic needles placed under the skin below the ipsilateral right pinna (reference electrode), at the vertex (active electrode) and contralateral pinna (ground electrode). The electrodes were connected to an amplifier (Grass, model $\mathrm{P} 15 \mathrm{D}$, gain $=1000$, filter settings $=100-3 \mathrm{kHz}$ ). A digital signal averager (Tracor Northern, model TN-1500) was used for signal averaging. The acoustic stimuli were presented in a closed acoustic system via a $1 / 2$ inch condensor microphone (Brüel and Kjaer) mated to a brass coupler with an $8.5 \mathrm{~cm} \times 0.3 \mathrm{~cm}$ (i.d.) silastic tube. The tube was inserted into the left external auditory meatus. Thresholds were obtained to tone bursts with a 10 ms duration, $1.0 \mathrm{~ms}$ rise time, at $32,16,8,4,2,1$ and $0.5 \mathrm{kHz}$. The stimulus repetition rate was $2 / \mathrm{s}$.
The stimulus intensity was decreased in $5 \mathrm{~dB}$ (SPL) steps, beginning at $90 \mathrm{~dB}$ (SPL). One set of 64 stimuli presentations was given at each intensity and 3 sets were given to determine threshold. Stimulus intensities were calibrated using a wave analyzer (Hewlett and Packard). The amplitude of wave 4 was followed as the response. The attenuator setting at which a response was last observed was recorded as the threshold. BAER data for each animal was plotted as threshold intensity, $\mathrm{dB}$ (SPL), versus stimulus frequency. The RAFRtested animals were then prepared for histological examination.

\section{Morphological measure}

The temporal bones from each animal of each treatment group and all controls were removed and the auditory bulla opened immediately. The round and oval windows and the apex of the cochlea were opened with a cowhorn explorer (a dental instrument consisting of a handle with 2 opposite helical sharpened probes at the ends). Inner ear tissues were fixed by perfusing $2.5 \%$ glutaraldehyde in phosphate buffer ( $\mathrm{pH}$ 7.4) through both windows. The tissue was placed in a $20 \mathrm{ml}$ glass vial on a 14 inch rotor at a $30^{\circ}$ angle and rotated at $12 \mathrm{rpm}$ for $1 \mathrm{~h}$. The tissue was then post-fixed with $1 \% \mathrm{OsO}_{4}$ in phosphate buffer $(\mathrm{pH}$ 7.4 ) in a similar manner for $30 \mathrm{~min}$. Cochleas were microdissected as described by Hawkins and Johnsson (1976). Individual turns of the organ of Corti were mounted on glass microscope slides in glycerol. Sensory hair cells of the organ of Corti were counted using a phase-contrast microscope (Wild, model M-20) equipped with a $50 \times$ objective lens. Cytocochleograms were prepared by plotting the percentage of hair cells remaining in each individual row, millimeter by millimeter, against distance $(\mathrm{mm})$ along the basilar membrane measured from the apex. BAER threshold data and cytocochleograms were compared in terms of frequency of functional change and position of the sensory hair cell loss along the basilar membrane. Average cytocochleograms were constructed by plotting the average hair cell loss in each hair cell row for each treatment group. Kidney weights were recorded at time of sacrifice and organ/body weight ratios calculated. Blood urea-nitrogen (BUN) and serum creatinine analyses (Faulkner 
and King, 1976) were performed on blood collected at sacrifice.

\section{Statistical analysis}

Student's $t$-test was used to compare means of experimental groups. Analysis of co-variance (Snedecor and Cochran, 1972) was used to compare regression lines of body weight gain data. The level of significance was $P \leqslant 0.05$ unless otherwise noted.

\section{Results}

Loss of outer hair cells occurred in all gentamicin-treated animals. Average cytocochleograms show treatment-group average hair cell loss at various positions along the length of the basilar membrane, expressed as percentage of total length in millimeters measured from the apex. Average cytocochleograms are presented in Fig. 1 for each $100 \mathrm{mg} / \mathrm{kg}$ treatment group. In each animal group, hair cell loss was greater after treatment with 100 $\mathrm{mg} / \mathrm{kg}$ gentamicin than after $80 \mathrm{mg} / \mathrm{kg}$. The three animal groups exhibited different degrees of response to gentamicin. The guinea pigs suffered more hair cell loss than the Fisher-344 rats, which, in turn, had more hair cell loss than the SpragueDawley rats. Hair cell loss after gentamicin treatment occurred in the basal region of the cochlea in all groups. The loss was greatest in the first row outer hair cells with the second and third rows showing progressively less loss. Photomicrographs of the organ of Corti from a Fisher-344 rat dosed with $100 \mathrm{mg} / \mathrm{kg}$ of gentamicin are shown in Fig. 2. The injury begins as outer hair cell loss in the first row (Fig. 2a). Complete hair cell loss was observed in all three rows of outer hair cells in the cochleas from animals most severely affected (Fig. 2b).

BAER threshold elevations in gentamicintreated animals occurred at frequencies corresponding to regions of the cochlea with hair cell loss. BAER threshold elevations in treated guinea pigs extended from the 32 to $4 \mathrm{kHz}$ regions. Treated Fisher-344 rats had BAER elevations in the 32 and $16 \mathrm{kHz}$ regions and treated SpragueDawley rats had threshold elevations in the 32 $\mathrm{kHz}$ region only. An individual cytocochleogram from a Fisher-344 rat treated with $100 \mathrm{mg} / \mathrm{kg}$

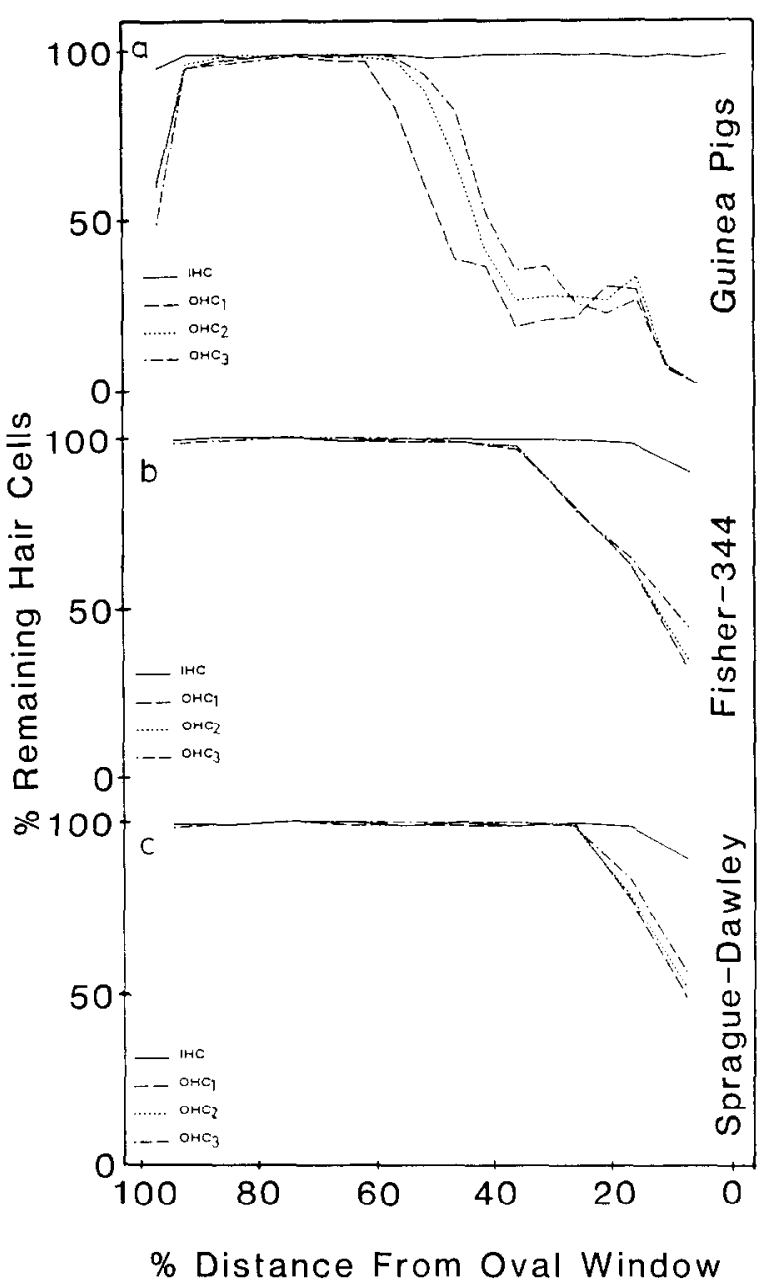

Fig. 1. Average cytocochleograms from (a) guinea pigs $(n=4)$, (b) Fisher-344 $(n=8)$ and (c) Sprague-Dawley rats $(n=8)$ dosed subcutaneously with $100 \mathrm{mg} / \mathrm{kg}$ of gentamicin for 14 days and sacrificed on day 11 after dosing ended. IHC, OHC1. $\mathrm{OHC} 2$ and $\mathrm{OHC} 3$ represent inner hair cells and outer hair cell rows 1,2 and 3, respectively.

gentamicin with its associated BAER threshold data is presented in Fig. 3. Cytocochleograms and BAER threshold graphs are presented together in Fig. 3 to facilitate comparison of the damaged region of the organ of Corti with frequency of threshold shift. The equating of a specific region of the cochlea with a specific frequency is only approximate. Regions of elevated threshold may not exactly correspond with regions of hair cell loss. This is because of the rigid criteria for scoring an individual hair cell as present or absent. 

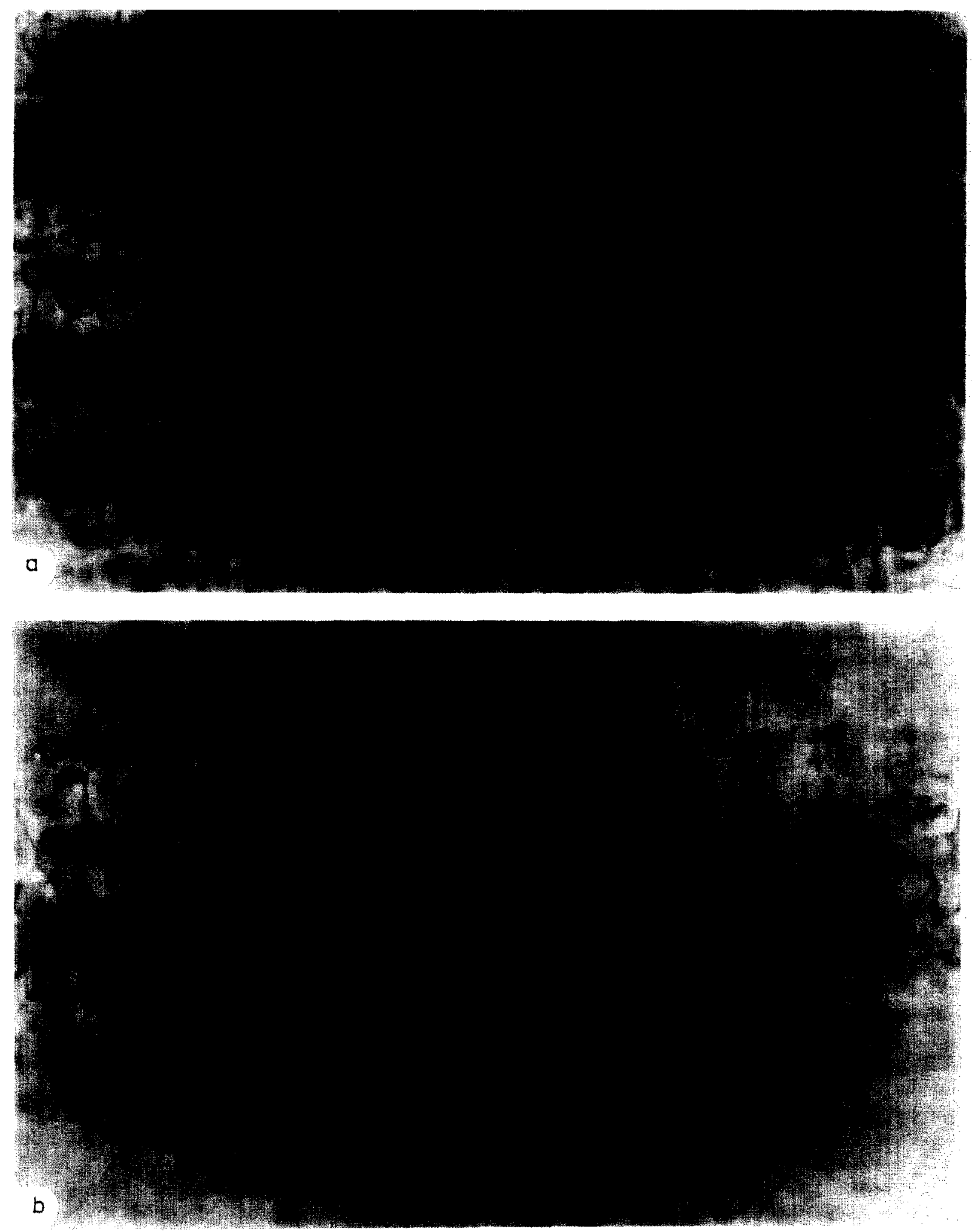

Fig. 2. Photomicrographs of the organ of Corti from a Fisher-344 rat dosed subcutaneously for 14 days with $100 \mathrm{mg} / \mathrm{kg}$ of gentamicin and sacrificed on day 11 after dosing ended. In a, scars are seen replacing several first row outer hair cells (arrows). In b, all the hair cells in the three rows of outer hair cells have degenerated. $1 \mathrm{HC}, \mathrm{OHCl}, \mathrm{OHC} 2$ and $\mathrm{OHC} 3$ indicate inner hair cells and outer hair cells, rows 1.2 and 3 , respectively. 
Hair cells which met the criteria for present, may still not be functional. These normal appearing but non-functional cells would contribute to threshold elevations but not hair cell loss. Only threshold elevations of greater than $10 \mathrm{~dB}$ (SPL) were considered significant.
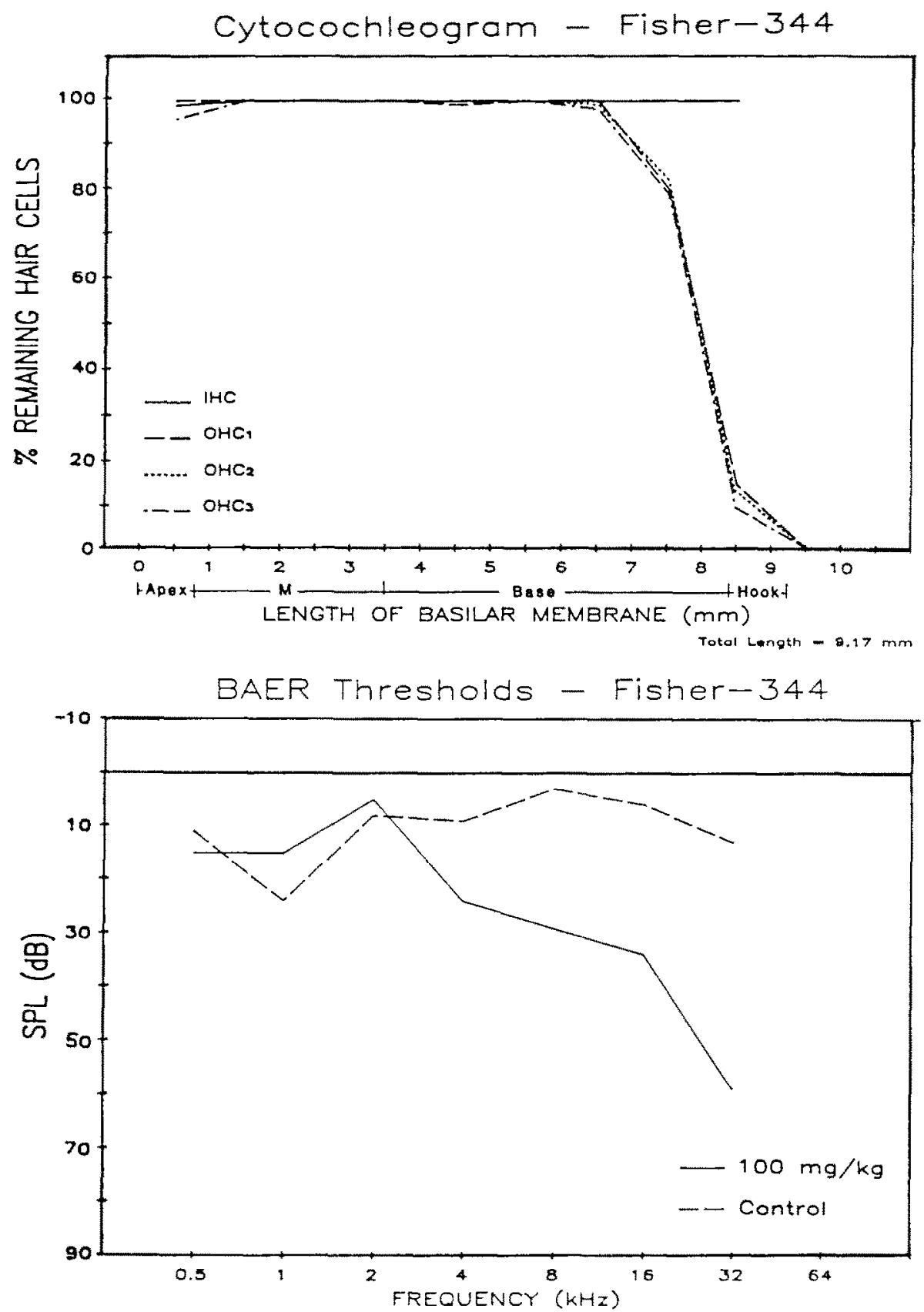

Fig. 3. Cytocochleogram and BAER threshold data from a Fisher-344 rat dosed subcutaneously for 14 days with $100 \mathrm{mg} / \mathrm{kg}$ of gentamicin and sacrificed on day 11 after dosing ended. Graphs are positioned to allow comparison of location of hair cell loss with the extent of threshold shift for the corresponding frequencies. Apex. T3, T2, base and hook are the individual cochlear turns. Control baseline is the average threshold data from 4 controls. 

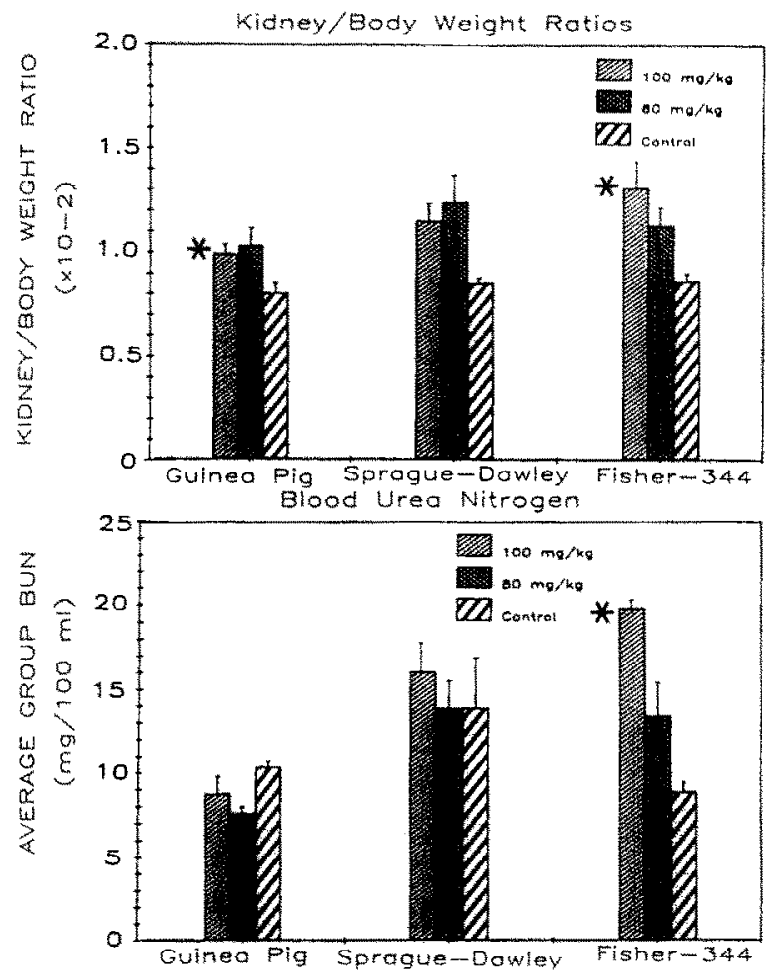

Fig. 4. Average treatment group blood urea-nitrogen and kidney weight/body weight ratios for guinea pigs $(n=4)$, Sprague-Dawley rats $(n=8)$ and Fisher-344 rats $(n=8)$ dosed subcutaneously for 14 days with 0,80 or $100 \mathrm{mg} / \mathrm{kg}$ of gentamicin and sacrificed on day 11 after dosing ended. * Significant difference from control, $P \leq 0.05$.

Controls of all three animal groups exhibited small amounts of hair cell loss and had measurable BAER threshold elevations. The hair cell loss in the controls was at the ends of the apical turn and hook, which is normal for these species. Threshold elevations were not greater than $10 \mathrm{~dB}$ (SPL) and therefore elevations of less than this were not considered significant.

Measures of nephrotoxicity showed a differential response among the three animal groups. Fisher-344 rats exhibited significant increases in BUN and kidney weight/body weight ratios (Fig. 4). The only other significant increase over controls was the kidney weight/body weight ratio for the $100 \mathrm{mg} / \mathrm{kg}$-treated guinea pigs. There were no measured nephrotoxic effects in the Sprague-Dawley rats or in serum creatinine levels in any treatment group. With respect to body weight gain, all gentamicin-treated groups gained significantly less weight than did their respective controls. The 100 $\mathrm{mg} / \mathrm{kg}$-treated groups gained less weight than did the $80 \mathrm{mg} / \mathrm{kg}$-treated groups.

No sign of vestibular toxicity was evident in any of the treated animals.

\section{Discussion}

Average cytocochleograms and BAER data for each animal group show a positive correlation between increasing severity of outer hair cell loss and increasing dose of gentamicin. Within each animal group, the $100 \mathrm{mg} / \mathrm{kg}$ treatment groups consistently exhibited greater hair cell loss than the $80 \mathrm{mg} / \mathrm{kg}$ treatment groups. The characteristic pattern of loss (first row $>$ second $>$ third) and position (basal portion of the organ of Corti) of aminoglycoside-induced hair cell loss is evident in all treatment groups. The similarity in the pattern of the outer hair cell loss suggests a similar mechanism of gentamicin ototoxicity in the three animal groups studied. Both functional and morphological data indicate that the Hartley albino guinea pig is more sensitive to the ototoxic effect of gentamicin than either the Fisher-344 rat or the Sprague-Dawley rat. The Fisher-344 rat is more sensitive to the ototoxic effect of gentamicin than is the Sprague-Dawley rat.

Nephrotoxicity was assessed by BUN and kidney weight/body weight determinations. The measure of kidney weight/body weight, although variable, provides an indication of an organspecific effect. BUN measurements provide an assessment of renal function: urea being cleared from the blood by the kidney. Decreases in body weight gain and increases in BUN and kidney weight/body weight ratio were measured in the Fisher-344 rats receiving $100 \mathrm{mg} / \mathrm{kg}$ of gentamicin. These results indicate that the Fisher-344 rat was the most sensitive of the three animal groups tested to the nephrotoxic effect of gentamicin. These data confirm previous literature reports that the Fisher-344 rat is more sensitive to the nephrotoxic effect of aminoglycoside antibiotics than the Sprague-Dawley rat (Humes et al., 1982). However, there is not a clear correlation between the magnitudes of the ototoxic and nephrotoxic responses in the three animal groups studied. This 
suggests that there are other factors involved, differing in the three animals tested in this study, which affect the relationship between nephrotoxicity and ototoxicity and their relative degree of severity.

The Fisher-344 rat appears to be a useful experimental animal in the study of aminoglycoside ototoxicity because it exhibits both functional and morphological changes at the same dose levels of gentamicin as the guinea pig. The Fisher-344 rat also exhibits both ototoxicity and nephrotoxicity after gentamicin exposure, making it a useful experimental animal for examining the relationship of these two types of toxicity. However, the sensitivity of the Fisher-344 rat to the nephrotoxic effects of gentamicin does limit its use in ototoxicity studies to dose levels at which the nephrotoxicity does not too severely compromise the health of the rat. Further studies of the factors that determine the different sensitivities of these animals to the effects of gentamicin might shed additional light on the mechanism of aminoglycoside ototoxicity.

\section{Acknowledgements}

The authors wish to thank Ms. Julie Davis for her instruction in microdissection and hair cell counting and Dr. J.E. Hawkins for his counsel in both designing these experiments and preparing this manuscript. Supported by NIEHS Training Grant no. 5T32E707062, Program Project Grant no. NS-05785 and Research Grant no. NS-050605.

\section{References}

Faulkner, W.R. and King, J.W. (1976) Renal function. In: N.W. Tietz (Ed.), Fundamentals of Clinical Chemistry, W.B. Saunders Pub. Co., Philadelphia, pp. 991-994.

Hawkins, J.E. Jr. (1976) Drug ototoxicity. In: W.D. Keidel and W.D. Neff (Eds.), Handbook of Sensory Physiology, Volume V. Auditory System, Part 3. Springer-Verlag, Berlin, pp. 707-748.

Hawkins, J.E. Jr. and Johnsson, L.-G. (1976) Microdissection and surface preparations of the inner ear. In: C.A. Smith and J.A. Vernon (Eds.), Handbook of Auditory and Vestibular Research Methods, Charles C. Thomas, Springfield, IL, pp. 5-51.

Humes, H.D., Weinberg, J.M. and Knauss, T.C. (1982) Clinical and pathophysiologic aspects of aminoglycoside nephrotoxicity. Am. J. Kidney Dis. 2, 5-29.

Snedecor, G.W. and Cochran, W.G. (1972) Comparison of Regression Lines. In: G.W. Snedecor and W.G. Cochran (Eds.), Statistical Methods, 6th Edition. Iowa State University Press, Ames, pp. 433-436. 